\title{
Çalışanların Bencillik Davranışlarının Motivasyonları Üzerindeki Etkisinde Performanslarının Aracı Etkisi
}

\author{
The Mediator Effect of the Performance of Employees on the Motivation of Selfish \\ Behavior
}

İbrahim DURMUŞ *

\begin{abstract}
$\ddot{O} Z$
Günümüz yoğun ve farklı çalışma ortamlarında çalışanlar farklı davranış özelliklerine sahip olmaktadır. Bu açıdan çalışanların bencil davranışları, performansları ve motivasyonları yaptıkları işler için önemli ve dikkate alınması gereken faktörlerdendir. Daha evvel gerçekleştirilen çalışmalarda genel olarak çalışanların motivasyonunun performansları üzerindeki etkileri ölçülmüş̧ür. Ayrıca önceki çalışmalarda çalışanların bencil (ben merkezli) davranışlarını ölçen fazla bir çalışmaya rastlanılmamıştır. Bu açıdan çalışmada daha önce gerçekleştirilen çalışmalardan farklı olarak çalışanların bencil davranışlarının motivasyonları üzerindeki etkisi ölçülürken çalışanların performansının aracı etkisi ortaya koyulmaya çalışılmıştır. Araşstrma sonuçlarında çallş̧anları bencil davranışları motivasyonlarını negatif ve anlamlı olarak etkilemişstir. Çalışanların bencil davranışları performansların yine negatif ve anlamlı olarak etkilemiştir. Çalışanların performansları ise motivasyonlarını pozitif ve anlamlı olarak etkilemişstir. Ek olarak çalışanların bencil davranışlarının motivasyonları üzerindeki etkisinde performanslarının da tam aracı etkiye sahip olduğu gözlemlenmiştir. Bu sonuçlar ile literatüre farklı bakış açıları kazandırılması amaçlanmaktadır.
\end{abstract}

\section{ANAHTAR KELIMELER}

Çalışanların Bencil Davranışları, Çalışanların Performansı, Çalışanların Motivasyonları

\begin{abstract}
In today's busy and different working environments, employees have different behavioral characteristics. In this respect, selfish behaviors, performances and motivations of employees are important and one of the factors to be taken into consideration for their work. In previous studies, the effects of motivation of employees on their performance were measured in general. In addition, the previous studies did not find many studies measuring selfish (self-centered) behaviors of employees. In this respect, unlike previous studies, the effect of employees 'selfish behaviors on their motivation was measured and the mediator effect of employees' performance was tried to be revealed. In the results of the research, the selfish behaviors of the employees had a negative and significant effect on their motivation. The selfish behaviors of the employees also affected their performance negatively and significantly. Employees' performances have a positive and significant effect on their motivation. In addition, it was observed that the performances of the employees had a full mediating effect on the motivation of selfish behaviors. With these results, it is aimed to gain different perspectives to the literature.
\end{abstract}

\section{KEYWORDS}

Selfish Behavior of Employees, Employee Performance, Motivation of Employees

\begin{tabular}{|c|c|c|}
\hline \multicolumn{2}{|c|}{ Makale Geliş Tarihi / Submission Date } & \multicolumn{1}{c|}{$\begin{array}{c}\text { Makale Kabul Tarihi / Date of Acceptance } \\
\text { 09.10.2019 }\end{array}$} \\
\hline \multirow{3}{*}{ Atıf } & $\begin{array}{l}\mid c \\
\text { Durmuş, İ. (2019). Çalışanların Bencillik Davranışlarının Motivasyonları Üzerindeki Etkisinde Performanslarının } \\
\end{array}$ & Aracı Etkisi. Selçuk Üniversitesi Sosyal Bilimler Meslek Yüksekokulu Dergisi, 22 (2), 853-866. \\
\hline
\end{tabular}

\footnotetext{
* Öğr. Gör. Gümüşhane Üniversitesi Sosyal Bilimler Meslek Yüksekokulu, ibrahimdurmus@gumushane.edu.tr, ORCID: 0000-0002-3872-2258
} 


\section{GİRIŞ}

Günümüz çalışma ortamında çalışanlar farklı özelliklere, farklı örgütsel değerlere ve farklı perspektiflere sahip olabilmektedirler. Bu açıdan çalışanlar çeşitli iç ve dış etmenlerin de etkisi ile iş yerlerinde daha bireysel yaklaşımlara yönelerek ben merkezli (bencil) davranışlar sergileyebilmektedirler. Çalışanların bencil hareket etmeleri performanslarını ve motivasyonlarını etkileyebilir. Ayrıca çalışanlar performansları sonucu elde ettikleri başarı veya başarısızlık hissiyatı onların motivasyonlarını şekillendirebilir. $\mathrm{Bu}$ açıdan çalışanların bencillik davranışları, performansları ve motivasyonları çalışma ortamlarının etkisi ile farklı perspektiflerin oluşmasına sebep olabilir.

Günümüz çalışma ortamında bireyler etik olmayan ve bencilce hareket ettikleri davranış biçimlerini azaltmaları gerekmektedir (Noval, 2016: 2). Çalışanların iş performansları çalışma ortamlarından ve çalışanların motivasyonlarından etkilenmektedir (Jayaweera, 2015: 275). Çalışanları motive etmek için yöneticilerin çalışanlarının özel ihtiyaçlarına uygun faktörleri etkili olarak harmanlamaları gerekir (DarteyBaah ve Amoako, 2011: 7). Bu açıdan çalışanların eğilimleri ve kalıcı değerleri ile diğer bireylerin yaşamlarında fark oluşturması, çalışanların motive olup olmadıklarını ortaya koyar (Grant, 2007: 394). Daha önce gerçekleştirilen çalışmalar çalışanların davranışlarının kaynakları ile nedenlerine ve bu davranışların yoğunluğu ile yönünü etkileyen sebeplere dikkat etmektedir (Yusoff vd., 2013: 19). Ayrıca daha evvel gerçekleştirilen çalışmalar genellikle çalışanların motivasyonlarının performansları üzerindeki etkilerini ölçmektedir. Araştırmada önceki çalışmalardan farklı olarak çalışanların bencil davranışlarının motivasyonları üzerindeki etkisinde performanslarının aracı etkisi ölçülmeye çalışılmıştır. Elde edilen sonuçlar ile literatüre farklı bakış açıları kazandırılabilir.

\section{KAVRAMSAL ÇERÇEVE}

\section{1.Çalışanların Ben Merkezli (Bencil) Davranışları}

Kaynak kıtlığı genellikle bencil davranışları (yani başkaları pahasına bireyin kendisine yarar sağlayan davranışlar) artırmaktadır. Bu tür davranışlar çoğu zaman bireyin kendisine en fazla faydayı sağlamaktadır (Roux vd., 2015: 617). Ancak çalışanların organizasyona yüksek derecede ihanet etmeleri organizasyonun hayatta kalmasını tehdit eder. Bu yanlışların bir kısmı bencil hareket eden bazı çalışanlar tarafından bir kısmı ise ortak hareket eden komplocu çalışanlar tarafindan meydana gelmektedir (Moberg, 1997: 44).

Çalışanların iş yerlerinde üstlenebilecekleri birden fazla rolü olabilir (Welbourne vd., 1998: 551). Bu roller açısından işyerlerinde çalışanların belirtilen işlerin ötesinde faaliyet göstermesi beklenemez (Tsui vd., 1997: 1094). Bunların yanında örgütsel iletişimde yapının liderliğii, kültürü, iş performansı gibi etmenler çalışanın işten ayrılma veya devam niyetinde hayati öneme sahiptir (Biswas, 2009: 614). Çalışanların işlerini yapma becerilerine zarar veren kaynak kesintisi, maaş dondurma, işten çıkarma gibi durumlar ise çalışanların fayda maliyetlerini artırarak çalışanlara daha fazla zarar verebilecektir (Wright, 2013: 743).

Rand'a göre bencillik bir erdemdir. O bencilliği bireysel olarak; yüzsüz, akılsız, sistem ile karşı karşıya gelme cesaretinde olan gerektiğinde kazanç pahasına istekli olarak değil de ihtiyaç olarak inançlarını takip eden kişiler olarak ifade etmiştir (Mintzberg vd., 2002: 69). Oysa Jensen ve Wygat (1990: 224) ise bir bireyin kendi çıkarlarını göz önüne almasının ahlaki olarak kabul edilemez bir davranış olduğunu ifade etmişlerdir. $\mathrm{Bu}$ faydacı durumun içsel ahlaktan ziyade bencillik ve kişisel çıkar eylemleri ile bağdaştı̆̆ını ifade etmişlerdir.

Literatürde bencillik ile ilgili çalışmalar incelendiğinde; Bevan ve Werhane (2015: 330) çalışmalarında Smith'in kişisel çıkar ile ilgili iki farklı durumu olduğunu ifade etmişlerdir. Birincisi bireyin duygularının, motivasyonunun ve yargılarının kendi çıkarlarına konu olmasıdır. İkinci olarak ise birey ve örgüt kıstasında bireyin kendi çıkarlarını göz önüne alarak başkalarına karşı ilgisiz davranabileceklerini veya bencil olabileceklerini ifade etmişlerdir. Onlar ayrıca sadece kendisi ile ilgilenen ve kendi çıkarlarını faaliyette bulunduğu iş yerinin çıkarlarından daha üstün tutabilecek bireylerin olabileceğini vurgulamışlardır. Chen (2014: 225) araştırmasında çalışanların kendilerine sunulan sınırlı kaynakların onların daha bencilce veya ahlak dişı düşünmelerine sebep olabileceğini ifade etmiş̧tir. Dubois ve diğerleri (2015: 447) ise çalışmalarında ahlaki olmayan davranışların genellikle bencillik ile işkili olduğu sonucuna ulaşmışlardır. Judge ve Ilies (2004: 154) çalışmalarında iş yerinde çalışanların ben merkezli olmalarının faydalı olup olmadıkları konusunda birçok tartışmanın olduğunu ifade etmişlerdir. Araştırmalarında bazı araştırmacıların çalışanların ben merkezli olmalarının zararlı olduğunu vurgulamışlardır. Forde ve Kennedy (1997: 281) ise araştırmaları sonucunda görev yönelimi yüksek olanların ve bencil olmayan kişilerin mağdur olma olasılıklarının daha yüksek olabildiğini ifade etmişlerdir. 


\section{2.Çalışanın Performansı}

Son yıllarda birçok firma bireysel ödemelerini çalışanların bireysel performans ölçülerine göre yapmaya başlamışlardır (Long, 2000: 487). Bu organizasyonlarda çalışan bireylerin yüksek performansları kariyerlerinin gelişimine katkıda bulunacaktır (Sani, 2013: 58). Bu açıdan performans değerlendirmeleri çalışanın gelişimini, kariyerini ve iktisadi getirilerini etkiler (Spence ve Keeping, 2010: 588). Ayrıca çalışanların grup düzeyinde yapılan araştırmaları dikkate alındığında ise gruplar ve çalışanlara etkisi arasında olumlu ilişkiler olduğu gözlemlenmiştir (Perter vd., 2003: 139).

Çalışanların performans ölçümlerinde onların yetenekleri, firsat değişkenleri ve çalışanların kişilik özellikleri motivasyonel değişkenler olarak etkili olabilir. Çalışanların performansları bu değişkenler ile birlikte örgütsel politikalar, teşvikler, ödül sistemleri ve prosedürler tarafından oluşturulan geri bildirimler arasındaki karmaşık etkileşim ile gerçekleşmektedir (Dvivedi, 1980: 574). Bu geri bildirimler çalışanların performansları açısından hatalara karşı uyarıcı nitelik taşır ve çalışanların hatalarını düzeltmelerine yardımcı olur (Fernandez ve Moldogaziev, 2013: 492).

Daha önce çalışanların performansı ile ilgili yapılan araştırmalarda çalışanların organizasyon içerisinde katılımlarının problemleri çözme becerilerini kullanmaları içi faydalı bir yol olduğunu ifade etmişlerdir (Abbas ve Yaqoob, 2009: 275). Chaurasia ve Shukla (2014: 344-346) çalışmalarında çalışan ile işveren arasındaki kaliteli ilişkilerin çalışanın psikolojik sermayesinin gelişmesini sağlayacağını ifade etmişlerdir. Ayrıca çalışmada yüksek düzeyde psikolojik sermayeye sahip olan çalışanların organizasyona daha fazla katılım sağlayabileceklerini ve daha iyi performans sergilemelerine teşvik edici bir nitelik taşıyabileceğini ifade etmişlerdir. Sattar ve diğerleri (2015: 90) ise araştırmaları sonucunda çalışanların organizasyonda katılımını artırmada eğitim, güçlendirme ve ödüllendirme gibi insan kaynakları uygulamalarının organizasyonun gücünü ve kalkınmasını sağlamasında çalışanların performanslarını ve memnuniyetlerini olumlu yönde etkilediğini ifade etmişlerdir. Cullen ve diğerleri (2014: 276) çalışmalarında organizasyonlarda belirsizliği anlamak için memnuniyet ve performansın direnişle mücadele ve değişimle başa çıkmada çok önemli olduğunu ifade etmişlerdir. Spreitzer ve Mishra (1999: 175) çalışmalarında çalışanların üst seviyelerde yönetime katılmalarının örgütsel performans ile ilişkili olduğu sonuçlarına ulaşmışlardır.

Çalışanların performansları ile ilgili diğer çalışmalar incelendiğinde; Akanbi (2011: 12) araştırması sonucunda çalışan performansının motivasyondaki artış ile geliştiği sonucuna ulaşmışlardır. Araştırmalarında ayrıca çalışanların iş yeri tarafından verilen ödüllere büyük değer verdiği, zira bu ödüller verilmediğinde çalışanların düşük performans gösterdiği ve işleri bağlı olmama durumlarından dolayı memnuniyetsizliklerini ifade etme eğiliminde oldukları sonuçlarına ulaşmıştır. Pandey (1988: 88-91) çalışması sonucunda güç ve bağl1lı motivasyonlarının performans ile pozitif bir ilişkiye sahip olduğunu ifade etmiştir. Ayrıca araştırması sonucunda yüksek düzeyde bir performans elde etmek için çalışanların etkili bir performans yeteneklerinin ve motivasyonlarının olması gerektiğini vurgulamıştır. Zameer ve diğerleri (2014: 298) araştırmaları sonucunda çalışanların iş zenginleştirme, iş güvencesine uygun maaş ve diğer ek teşvikler ile çalışanların motive edilmesinin performanslarını olumlu yönde etkilediği sonucuna ulaşı1mıştır. Uzonna (2013: 209-210) araştırması sonucunda çalışanların motivasyonu ve performansları açısından; Maslow'un ihtiyaçlar hiyerarşisinin ve Herzberg'in iki faktörlü teorisi gibi teorilerin temel bileşenlerinin iş yerleri (veya yöneticiler) tarafından çalışanlarını gerçek anlamda anlayabilmeleri için dikkat edilmesi gereken teoriler olduğunu ifade etmiştir. Araştırmasında ayrıca bu kavramların iyi kavranması ve uygulanması ile çalışanların daha yüksek performans ortaya koyabileceklerini vurgulamıştır.

\section{3.Çalışanların Motivasyonu}

Motivasyon; davranışlara enerji veren, davranışları yönlendiren ve davranışı sürdüren durum anlamına gelmektedir. Yani bireyin davranışsal bir durumda sergilediği çabanın derecesi ve türü olarak ifade edilebilir. Motivasyon ayrıca bu çabanın yönü ve kalitesi ile de ilgilidir (Perry ve Porter, 1982: 89).

Günümüzde kuruluşların en büyük problemlerinden biri çalışan personelini başarıya yönelik istekli ve ilgili olmalarını gerektiren teknikleri geliştirmemeleridir. Bunu için yöneticilerin öncelikli görevi çalışanlarını en üst düzeyde performans sağlayacak şekilde motive etmeleridir (Azar ve Shafighi, 2013: 433). Yöneticilerin iş yerlerinin performanslarını artırmaları ve yeteneklerini kullanabilmeleri için çalışanları neyin motive ettiğini belirlemeleri gerekir. Örneğin çalışanlara verilen ücret, eğitim, etkili iletişim, çalışanların kıdem alması ve sağlıklı bir çalışma ortamı gibi etmenler etkili olabilir (Anyim vd., 2012: 37-38). Ayrıca çalışanların iş yerlerindeki motivasyonlarını geliştirmelerinde liderlik davranışı sergileyen bireylerde önemlidir. Yani liderin güveni, desteği, hedef vurgusu, grup etkileşimi gibi psikolojik ve hiyerarşik etkilerde davranışlar çalışanların iş motivasyonunu ve verimliliklerini etkileyebilmektedir (Tyagi, 1985: 77). Bu açıdan örgütün çevresel olarak

Selçuk Üniversitesi Sosyal Bilimler Meslek Yüksekokulu Dergisi, Yıl: 2019 Cilt: 22 Sayı:2 
iyileştirilmesinde motivasyon, örgüt kültürü tarafından destek görebilir veya görmeyebilir (Govindarajulu ve Daily, 2004: 366).

Peter Drucker, uzun bir zaman önce insanları kontrol etmekten çok insanları motive etmek için hedeflerin kullanılması gerektiğini vurgulamıştır (Hijazi, 1999: 906). Herzberg (1959) ise çalışanların motivasyon ile ilgili iş faktörlerini; tanımlama, başarı, büyüme olasılığı, ilerleme, sorumluluk ve kendi kendine çalışma olarak sıralamıştır (Akt., Tietjen ve Myers, 1998: 226). Bu açıdan bir organizasyonda çalışanların işlerine (üretime) yönelik motivasyonlarını; ücret, statü veya çalışanların o organizasyona karşı hissettikleri etkili olabilir (Akaoka, 1983: 31) .

Daha evvel çalışanların motivasyonu ile ilgili yapılan çalışmalar incelendiğinde; Thompson (1996: 189) çalışması sonucunda en başarılı kuruluşlardaki özelliğin hem kurumun hem de çalışanın başarısında iletişim kurma konusunda yetenekli bir liderin varlığının olduğunu ortaya koymuştur. Corey (1973: 39) ise çalışmasında çalışanları motive edici faktörler arasında; çalışan ile işveren arasındaki iyi iletişim, denetim yetkinliği, tatmin edici eğitim olanakları, yeterli düzeyde tanınma, işten zevk alma, iş süresindeki güvenlik, çalışanlar arasındaki olumlu ilişkiler ve çalışanların teşvik edilmesi gibi faktörlerin yer aldığını ifade etmiştir. Hitka ve Balazova (2015: 115) araştırmaları sonucunda çalışanların temel maaşları, daha fazla parasal ödül ve farklı eğitim biçimleri, iş güvenliği ve sosyal politika yolu ile motive dildiklerini ortaya koymuşlardır.

Memnuniyet motivasyon değildir (Manners vd., 1997: 32). Bu açıdan Padaki (1984: 482) çalışmasında çalışanların yaptıkları işlerin özelliklerine göre motivasyonlarını ve memnuniyetlerini etkileyen psikolojik durumların olduğunu ifade etmiştir. Motivasyon ve memnuniyet deneyimlerinin 'duygusal durumlar' ve 'deneyimler' ile ifade edilebileceğini vurgulamıştır. Ayrıca çalışmasında bu değişkenler arasındaki farklılaşmanın önemli düzeyde olmadığını çünkü bu durumların ortak duyguların ürünü olduğunu ifade etmiştir. Bu açıdan Ali ve Ahmed (2009: 278) araştırmalarının sonucunda ödül ve takdir ile motivasyon ve memnuniyet arasında istatistiksel olarak anlamlı ilişkiler elde etmişlerdir. Onlar çalışanlara verilen ödüllerin ve takdirin motivasyonları üzerinde olumlu bir etkisinin olabileceğine ve bu durumun çalışanların daha fazla iş performansı göstermelerine sebep olabileceğini vurgulamışlardır.

Çalışanların motivasyonu ile ilgili gerçekleştirilen diğer çalışmalar incelendiğinde; Bright (2007. 374) çalışması sonucunda kamu hizmetleri motivasyonu ile kamu çalışanlarının iş performansları üzerinde doğrudan bir etkisinin olmadığı sonucuna ulaşmıştır. Ayrıca çalışmasında çalışanlar ve örgütleri arasındaki uyum arttıkça iş performanslarının da arttığını ifade etmiş̧ir. Benston (1963: 354) ise çalışmasında yerinden yönetimin motivasyonun etkinliğine katkıda bulunduğunu ifade etmiştir. Lu (1999: 70) ise araştırmas1 sonucunda iş motivasyonunun çalışanın refahı üzerinde önemli etkilerinin olduğu sonucuna ulaşmıştır. Ayrıca çalışmada içsel motivasyonun genel iş tatminine olumlu katkıları olurken dışsal motivasyonun depresyona olumlu etkilerinin olduğu sonuçlarını ortaya koymuştur. Osterloh ve Frey (2000: 546) çalışmalarında içsel motivasyonun firmalar için önemli olduğunu ifade ederek içsel motivasyonda güven oluşturabilmek için bilgi üretme ve bilgiyi aktarma olanaklarının etkili bir şekilde yerine getirilmesi gerektiğini ifade etmişlerdir. Muogbo (2013: 148) ise çalışmasında bir organizasyonda çalışanlara verilen dışsal motivasyonun çalışanların performansı üzerinde önemli bir etkisinin olduğu sonucuna ulaşmıştır.

Çalışanların motivasyon ve performans değişkenleri dikkate alındığında; Wiley (1997: 276) araştırması sonucunda çalışanların işlerine yönelik kendilerinin motive olmasını sağlayan beş değişkeni; iyi bir ücret, gerçekleştirilen işte takdir görme, yapılan işin güvenliği, organizasyonda tanıtım ile büyüme ve ilginç bir çalışma olarak sıralandığını gözlemlemiştir. Manzoor (2011: 37) ise araştırmasında çalışanların performansı temel olarak değerlendirildiğinde çalışanların motivasyonu, çalışan memnuniyeti, tazminat, eğitim ve gelişim, iş güvenliği ve organizasyon yapısı gibi birçok faktöre bağlı olduğunu ifade etmiştir. Gerçekleştirilen araştırmada ise çalışanların performansları ve motivasyonlarının yanında bencillik davranışlarına da odaklanılmıştır. Daha evvel gerçekleştirilen araştırmalarda çalışanların bencillik (ben merkezli olma) davranışları fazla çalışılmamıştır. İş yerlerinde çalışan bireyler günümüz şartlarında birçok kez kolektif hareket edememekte bireyselliklerini ön plana çıkarabilmektedirler. Ayrıca önceki çalışmaların birçoğunda çalışanın motivasyonunun performansı üzerindeki etkileri ölçülmüşken araştırmada çalışanların performanslarının motivasyonları üzerindeki etkileri araştırılmıştır. Sonuç olarak organizasyonlarda yapılan işlerin performans açısından yerine getirilmesi çalışanların motivasyonunu etkileyebilir.

\section{ARAŞTIRMA YÖNTEMI}

\section{1.Çalışmanın Önem Derecesi ve Amacı}

Günümüzde birçok farklı alanda çalışan bireyler çalışma ortamlarından ötürü bencil davranış şekilleri ortaya koyabilmektedirler. Çalışanların bu bencil davranışları hem motivasyonlarını hem de performanslarını şekillendirebilmektedir. $\mathrm{Bu}$ açıdan araştırmada çalışanların bencil davranışlarının performanslarının 
üzerindeki etkisi ölçülürken motivasyonlarının da aracı etkisi ortaya koyulması amaçlanmaktadır. Elde edilecek sonuçlar ile literatüre farklı bakış açıları kazandırılabilir.

\section{2.Örneklem Süreci}

Araştırmanın bulguları ve analizlerine ilişkin veriler 2019 yılı içerisinde Türkiye'de Doğu Anadolu ve Doğu Karadeniz Bölgelerinde kamuda (Üniversite ve SGK çalışanları) ve özel sektörde (giyim mağazaları ve farklı hizmet sektörlerinde -çağrı merkezi gibi-) faaliyette bulunan 412 çalışana elektronik anket yönetimi ile erişim sağlanarak geri dönüşüm alınmıştır. Çalışmada çalışanların bencil davranışları, motivasyonları ve performansları ölçülmeye çalışılmıştır. Çalışmada AMOS 24 ve SPSS 21 paket programlarından faydalanılmış ve elde edilen sonuçlar yorumlanmıştır.

\subsection{Veri Toplama Yöntemi}

Çalışmada kullanılan ölçekler araştırmanın konusu ile ilgili daha evvel gerçekleştirilen benzer çalışmalar dikkate alınarak araştırma ölçeğine eklenmiştir. Çalışma ölçeğinde kullanılan faktörler çalışanların iş yeri ortamı ve çalışanların kültürel değerleri dikkate alınarak uygulamaya koyulmuştur. İlgili ölçekler ve kaynaklar tablo 1'de belirtilmiştir.

Tablo 1: Araştırmanın Ölçekleri

\begin{tabular}{|l|c|l|}
\hline \multicolumn{1}{|c|}{ Ölçek } & Maddeler & \multicolumn{1}{c|}{ Kaynak } \\
\hline Çalışanların Ben Merkezli (Bencil) Davranışları (B) & 4 & Forde ve Kennedy, 1997: 274 \\
\hline Çalışanların Performansı (P) & 4 & Gong vd., 2009: 769 \\
\hline Çalışanların Motivasyonları (M) & 5 & Sengupta, 2011: 114 \\
\hline
\end{tabular}

Araştırmanın ölçekleri ortaya koyulurken daha önce gerçekleştirilen çalışmalar dikkate alınmıştır. Bu çalışmalardan çalışanların bencillik davranışlarını ortaya koyan ölçek Forde ve Kennedy (1997)'nin çalışmasından, çalışanların motivasyonlarını ölçmek için ortaya koyulan sorular Sengupta (2011)'nın araştırmasından ve çalışanların performansını ifade eden ölçek soruları ise Gong ve diğerlerinin (2009) çalışmalarında ifade ettikleri ölçeklerden alınarak ilgili araştırmaya uyarlanmıştır.

\subsection{Araştırma Modeli}

Araştırma modeli oluşturulurken literatürde daha evvel konu ile ilgili çalışmalar; Forde ve Kennedy (1997), Barrick ve diğerlerinin (2002), Gong ve diğerlerinin (2009), Sengupta (2011), Lin ve Liu (2012) ve Guo ve diğerlerinin (2014) çalışmaları dikkate alınarak araştırma modeli aşağıda şekil 1'deki gibi ifade edilmiştir.

Şekil 1: Çalışmanın Hipotez Modeli

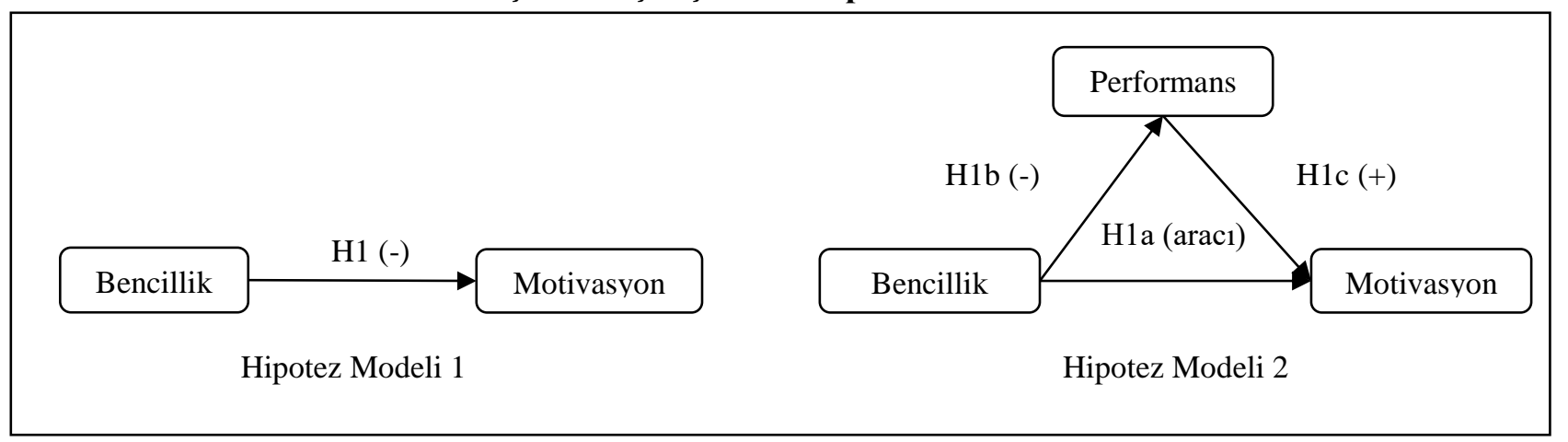

Araştırma ile oluşturulan hipotezler aşağıda ifade edilmiştir: etkiler.

H1: Çalışanların iş yerlerindeki bencillik davranışları motivasyonlarını negatif ve anlamlı olarak

H1a: Çalışanların iş yerlerindeki bencillik davranışlarının motivasyonları üzerindeki etkisinde performanslarl aracı etkiye sahiptir. etkiler.

H1b: Çalışanların iş yerlerindeki bencillik davranışları performanslarını negatif ve anlamlı olarak

H1c: Çalışanların iş yerlerindeki performansları motivasyonlarını pozitif ve anlamlı olarak etkiler. 


\subsection{Analiz ve Bulgular}

Çalışmanın analiz ve bulgularını ifade eden değişkenler aşağıdaki başlıklar altında detaylı bir şekilde incelenmiştir.

\subsubsection{Demografik Veriler}

Araştırma ile ilgili demografik verileri aşağıda tablo2'de ortaya koyulmuştur.

Tablo2: Araştırmada Elde Edilen Demografik Sonuçlar

\begin{tabular}{|c|c|c|c|c|c|}
\hline Yaş & Frekans & Yüzde & Cinsiyet & Frekans & Yüzde \\
\hline 23 veya altı yaş & 14 & 3,4 & Kadın & 234 & 56,8 \\
\hline $24-28$ yaş aralığ1 & 113 & 27,4 & Erkek & 178 & 43,2 \\
\hline 29-33 yaş aralığ & 135 & 32,8 & Toplam & 412 & 100,0 \\
\hline 34-38 yaş aralığ & 83 & 20,1 & & & \\
\hline $39-43$ yaş aralığ & 29 & 7,0 & Eğitim Durumu & Frekans & Yüzde \\
\hline 44 ve üzeri yaş aralığ & 38 & 9,2 & İlköğretim & 2 & ,4 \\
\hline Toplam & 412 & 100,0 & Ortaokul veya Lise & 14 & 3,4 \\
\hline Aylık Gelir & Frekans & Yüzde & Ön lisans & 14 & 3,4 \\
\hline $2000 \mathrm{TL}$ ve alt1 & 32 & 7,8 & Lisans & 177 & 43,0 \\
\hline 2001-3600 TL & 71 & 17,2 & Lisansüstü & 205 & 49,8 \\
\hline $3601-5200 \mathrm{TL}$ & 149 & 36,2 & Toplam & 412 & 100,0 \\
\hline $5201-6800 \mathrm{TL}$ & 107 & 25,8 & & & \\
\hline 6801 ve üzeri & 53 & 13,0 & İdari Görev & Frekans & Yüzde \\
\hline Toplam & 412 & 100,0 & Evet & 97 & 23,5 \\
\hline Tecrübe & Frekans & Yüzde & Hayır & 315 & 76,5 \\
\hline $1-4$ yll tecrübe & 131 & 31,8 & Toplam & 412 & 100,0 \\
\hline 5-8 yil tecrübe & 138 & 33,5 & & & \\
\hline 9-12 y1l tecrübe & 56 & 13,6 & Kurum & Frekans & Yüzde \\
\hline 13-16 yıl tecrübe & 29 & 7,0 & Kamu & 308 & 74,8 \\
\hline 17 yıl ve üzeri tecrübe & 58 & 14,1 & Özel Sektör & 104 & 25,2 \\
\hline Toplam & 412 & 100,0 & Toplam & 412 & 100,0 \\
\hline
\end{tabular}

Araştırmada tablo 2'de elde edilen sonuçlar dikkate alındığında; çalışmaya katılanların büyük kısmı kadın (234 çalışan - \%56,8) çalışanlardan oluşmaktadır. Katılımcılar yaşları açısından değerlendirildiğinde 29-33 yaş aralığı $(135$ çalışan - \%32,8) ve 24-28 yaş aralığına (113 çalışan - \%27,4) sahip olan çalışanlar çoğunluğu oluşturmaktadır. Çalışanların geliri dikkate alındığında ise en fazla 3601 - 5200 TL $(149$ çalışan - \% 36,2) gelire sahip olanların daha fazla olduğu görülmektedir. Eğitim durumları incelendiğinde lisansüstü (205 çalışan - \% 49,8) eğitime sahip olanların çoğunluğu oluşturduğu gözlemlenmektedir. Çalışanların en fazla 5-8 yıl $(138$ çalışan - \%33,5) ve 1-4 yıl $(131$ çalışan - \% 31,8) arası tecrübeye sahip oldukları, idari görev olarak birçoğunun idari görevinin olmadığı (315 çalışan - \% 76,5) ve birçoğunun kamuda $(308$ çalışan - \% 74,8) çalıştığı sonuçlarına ulaşılmaktadır.

\subsubsection{Faktör ve Güvenilirlik Analizleri}

Araştırmada meydana getirilen model SPSS 21 ve AMOS 24 paket programları yardımı ile analiz edilmiştir. Analiz sonuçlarında araştırmada ölçme aracı olarak kullanılan 13 maddenin ana kütleye uygulanması sonucu çalışmanın tamamının güvenilirliği ortaya koyan Cronbach Alpha değeri = ,766 ve geçerliliğini ortaya koyan Kaiser-Meyer-Olkin değeri $=, 777$ olarak hesaplanmıştır. Araştırma modelinin toplam varyansa katkısı ise 56,490 olarak hesaplanmıştır. Elde edilen sonuçlar çalışmanın geçerli ve güvenilir sonuçlar ortaya koyduğunu göstermektedir (Jayaweera, 2015: 273; Battal vd., 2017: 19). Araştırmada her bir ölçeğin faktör yüklerine ilişkin geçerlilik ve güvenilirlik sonuçları aşağıda tablo3’te belirtilmiştir.

\section{Tablo3: Faktör ve Güvenilirlikler}

\begin{tabular}{|l|c|c|c|}
\hline \multicolumn{1}{|c|}{ Faktörler } & Maddeler & Cronbach's Alpha & KMO \\
\hline Çalışanların Bencil Davranışları (B) & 4 &, 726 &, 700 \\
\hline Çalışanların Motivasyonları (M) & 5 &, 716 &, 710 \\
\hline Çalışanların Performansı (P) & 4 &, 783 &, 752 \\
\hline
\end{tabular}

Tablo3'te elde edilen faktör ve güvenilirlik analizleri sonuçlarında çalışanların bencil davranışlarını, motivasyonlarını ve performanslarını ifade eden ölçeklerin kabul edilebilir sınırlar içerisinde olduğu 
görülmektedir. İlgili sonuçlar tablo 3 ve tablo 4'te ifade edilmiştir (Zhang vd., 2014: 429-432; Chiang ve Hsieh, 2012: 185; Kuvaas, 2006: 517-518). Araştırma ölçeklerinde en fazla güvenilirlik ve geçerlilik çalışanların performansı ölçeği ile elde edilmiştir.

Tablo 4: Araştırmanın Güvenilirliği ile Faktör Analizleri Verileri

\begin{tabular}{|c|c|c|c|c|c|}
\hline \multicolumn{2}{|r|}{ Araştırma Faktörleri } & Alpha & Açıklanan & Faktör & $\overline{\mathbf{R}^{2}}$ \\
\hline B1 & $\begin{array}{l}\text { Başkalarının işlerini zorlaştırsa da iş yerimde önce kendime } \\
\text { bakarım. }\end{array}$ & \multirow{4}{*}{$\begin{array}{c}, 726 \\
(\% 72,6)\end{array}$} & \multirow{4}{*}{56,168} & 0.67 & 0.45 \\
\hline $\mathbf{B 2}$ & İş yerimde çalışma arkadaşlarıma karşı sempatik değilim. & & & 0.68 & 0.46 \\
\hline $\mathbf{B 3}$ & $\begin{array}{l}\text { Çalışma arkadaşlarımı üzdüğüm hususlar var ise bu onların } \\
\text { sorunu benim değil. }\end{array}$ & & & 0.79 & 0.62 \\
\hline B4 & $\begin{array}{l}\text { İş yerimde çalışma arkadaşlarıma problem oluştursa da } \\
\text { istediklerimi yaparım. }\end{array}$ & & & 0.84 & 0.71 \\
\hline M1 & Zihnimin sakin olması iş yerimdeki etkinliğimi artırır. & \multirow{5}{*}{$\begin{array}{c}, 716 \\
(\% 71,6)\end{array}$} & \multirow{5}{*}{49,074} & 0.66 & 0.44 \\
\hline M2 & İş yerimde iç huzurun olmasını severim. & & & 0.65 & 0.42 \\
\hline M3 & İşim yaşamın amacını anlamama yardımcı olur. & & & 0.50 & 0.25 \\
\hline M4 & İş yerimde iyi bir performans için disiplin gereklidir. & & & 0.72 & 0.52 \\
\hline M5 & 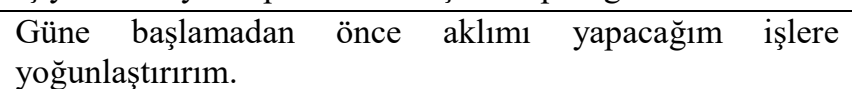 & & & 0.80 & 0.64 \\
\hline $\mathbf{P 1}$ & $\begin{array}{l}\text { İs yerimin genel performansına önemli katkılarda } \\
\text { bulunurum. }\end{array}$ & \multirow{4}{*}{$\begin{array}{c}, 783 \\
(\% 78,3)\end{array}$} & \multirow{4}{*}{61,343} & 0.81 & 0.66 \\
\hline $\mathbf{P 2}$ & Çalışma birimimin en iyi çalışanlarından biriyim. & & & 0.83 & 0.69 \\
\hline $\mathbf{P 3}$ & İşim ile ilgili görevlerimi zamanında tamamlarım. & & & 0.58 & 0.34 \\
\hline $\mathbf{P 4}$ & $\begin{array}{l}\text { İş yerimdeki performansım yöneticimin beklentisini her } \\
\text { zaman karşılar. }\end{array}$ & & & 0.68 & 0.46 \\
\hline
\end{tabular}

Tablo 4'te ifade edilen analiz sonuçları dikkate alındığında; açıklanan varyansa en fazla katkı çalışanların performans $(61,343)$ ölçeğinden, sonra çalışanların bencilliği $(56,168)$ ölçeğinden ve çalışanların motivasyonu $(49,074)$ ölçeklerinden sağlandığ 1 gözlemlenmektedir. Çalışma ölçekleri güvenilirlikleri açısından değerlendirildiğinde çalışanların performansı ölçeği en fazla güvenilirliğe $(, 783)$ sahip olmuştur. Devamında araştırmanın güvenilirliği çalışanların bencillik davranışları $(, 726)$ ve çalışanların motivasyonları $(, 716)$ olarak sıralanmıştır.

Araştırmaya faktör yükleri açısından bakıldığında ise, çalışanların bencillik davranışı ölçeğine en fazla katkıyı B4 (0.84) sorusu sağlamıştır. Bu seçenek ile çalışanların iş yerlerinde çalışma arkadaşlarına problem oluştursa da istediklerini yaptıklarını ifade etmişlerdir. Çalışanların motivasyon ölçeği dikkate alındığında ise ölçeğe en fazla katkıyı M5 (0.80) seçeneği sağlamıştır. Bu seçenekte ise çalışanlar güne başlamadan önce aklını yapacakları işlere yoğunlaştırdıklarını ifade etmişlerdir. Çalışanların performans ölçeği incelendiğinde en fazla katkıyı P2 (0.83) seçeneği sağlamıştır. Bu seçenekte ise çalışanlar çalışma birimlerinin en iyi çalışanlarından biri olduklarını ifade etmişlerdir.

\subsubsection{Araştırma Model 1'in Yapısal Eşitlik Modeli Sonuçları}

Gerçekleştirilen çalışmaya ilişkin araştırma modeli 1'in AMOS analiz sonuçları tablo 5'te ifade edilmiştir. Tabloda daha önce literatürde gerçekleştirilen çalışmalar ile kabul edilen indeksler, kabul edilen değer aralıkları ve araştırma uygulanması ile elde edilen ölçüm modeli sonuçları dikkate alınarak analizler gerçekleştirilmiştir. Ayrıca uygulama sonuçları ile elde edilen veriler literatürdeki benzer çalışmalar dikkate alınarak yorumlanmıştır. 
Tablo 5: Literatür İndeksleri ve Model 1'in Araştırma Modeli Sonuçları

\begin{tabular}{|c|c|c|}
\hline Literatür İndeksleri & Kabul Edilebilir Değerler & Araştırma Modeli \\
\hline RMSEA & $<, 05-, 08 \leq$ &, 072 \\
\hline CMIN/DF & $0<\chi 2 /$ sd $\leq 5$ & 3,743 \\
\hline IFI & $>, 90$ &, 923 \\
\hline TLI & $>, 90$ &, 888 \\
\hline CFI & $>, 90$ &, 922 \\
\hline RMR & $<, 1$ &, 050 \\
\hline
\end{tabular}

Araştırmada tablo 5'te ulaşılan sonuçlar dikkate alındığında araştırmanın TLI değeri dışında diğer değerlerinin literatürde kabul edilebilir sınırlar içerisinde yer aldığı gözlemlenmektedir. Bu sonuçlar bütün olarak incelendiğinde araştırmanın uygulanabilir olduğunu ortaya koymaktadır (Guo vd., 2014: 735; Vandenabeele, 2016: 34).

Tablo 6: Araştırmanın Regression Ölçüm Modeli Sonuçları

\begin{tabular}{|c|c|c|c|c|c|}
\hline $\begin{array}{c}\text { Modeldeki } \\
\text { Iliş̧kilendirmeler }\end{array}$ & $\begin{array}{c}\text { Standardize } \\
\boldsymbol{\beta}\end{array}$ & $\mathbf{S . E .}$ & $\mathbf{p}$ & Hipotez & Açıklama \\
\hline $\mathrm{B} \rightarrow \mathrm{M}$ &,- 107 &, 036 &, 003 & H1 & Kabul \\
\hline
\end{tabular}

Çalışma tablo 6'da regression ölçüm modeli sonuçları dikkate alındığında çalışanların bencillik davranışlarının motivasyonları üzerinde negatif $(-, 107)$ ve anlamlı $(, 003)$ etkilerinin olduğu görülmektedir. Model 1'e ait bu sonuçlar aşağıda şekil 2'de gösterilmiştir ve elde edilen sonuçlar yorumlanmıştır.

\section{Şekil 2: Model 1 Yapısal Eşitlik Modeli Sonucu}

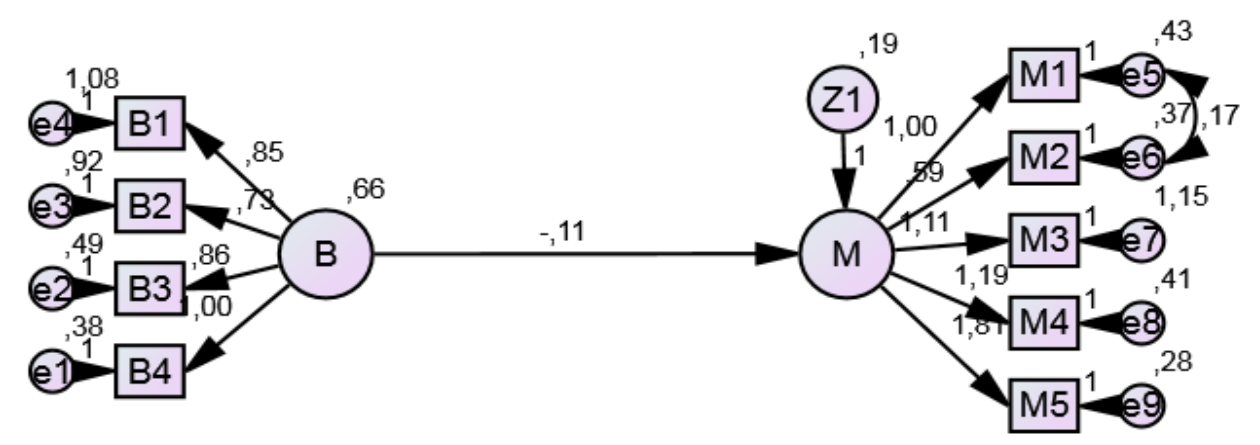

Şekil 2'de elde edilen sonuçlar dikkate alındığında; araştırma hipotez modelinde çalışanların motivasyon değerlerini ölçen M1 ve M2 değişkenleri üzerinde modifikasyon gerçekleştirilmiştir. Bu durum model 1 ölçeğinin AMOS uygulama sonuçları ile literatürde kabul edilebilir seviyeler içerisinde uyumlu olabilmesini sağlamak için gerçekleştirilmiştir.

Araştırmada model 1'de çalışanların bencillik davranışlarının motivasyonları üzerinde negatif ve anlamlı etkilerinin olduğu sonucuna ulaşılmıştır. Bu sonuç oluşturulan h1 hipotezinin kabul edildiğini ortaya koymaktadır. Bu sonuç iş yerlerinde çalışanların ben merkezli hareket etmelerinin ilginç bir şekilde aslında kendi motivasyonlarını olumsuz olarak etkilediğini ortaya koymaktadır. Bu sonuç çalışan bireylerin bencil hareket etmelerinin motivasyonlarını düşürücü bir etki uyandırdı̆ııı ortaya koymaktadır.

\subsubsection{Araştırma Model 2'nin Yapısal Eşitlik Modeli Sonuçları}

Araştırma model 2'ye ait elde edilen AMOS sonuçları aşağıda tablo7'de belirtilmiş ve elde edilen sonuçlar literatür çerçevesinde yorumlanmıştır.

Tablo 7: Literatür İndeksleri ve Araştırma Modeli Sonuçları 


\begin{tabular}{|c|c|c|}
\hline Literatür İndeksleri & Kabul Edilebilir Değerler & Araştırma Modeli \\
\hline RMSEA & $<, 05-, 08 \leq$ &, 066 \\
\hline CMIN/DF & $0<\chi 2 /$ sd $\leq 5$ & 3,277 \\
\hline TLI & $>, 90$ &, 887 \\
\hline IFI & $>, 90$ &, 914 \\
\hline CFI & $>, 90$ &, 913 \\
\hline RMR & $<, 1$ &, 053 \\
\hline
\end{tabular}

Araştırmada Yapısal Eşitlik Modeli sonuçları incelendiğinde modelin TLI değeri dışında literatürde kabul edilen değerler içerinde yer aldığ 1 gözlemlenmektedir. Bu sonuçlar araştırma modelinin uygulanabilir olduğunu ortaya koymaktadır (Barrick vd., 2002: 5; Yuan ve Woodman, 2010: 333).

Tablo 8: Araştırmanın Aracı Etkili Regression Ölçüm Modeli Sonuçları

\begin{tabular}{|r|r|c|c|c|c|}
\hline Modeldeki İlişkilendirmeler & Standardize $\boldsymbol{\beta}$ & S.E. & $\mathbf{p}$ & Hipotez & Açılama \\
\hline $\mathrm{B} \rightarrow \mathrm{P}$ &,- 085 &, 037 &, 019 & H1b & Kabul \\
\hline $\mathrm{P} \rightarrow \mathrm{M}$ &, 793 &, 115 & $* * *$ & H1c & Kabul \\
\hline $\mathrm{B} \rightarrow \mathrm{M}$ &,- 063 &, 036 &, 078 & H1a & Kabul \\
\hline
\end{tabular}

Araştırmada daha önce gerçekleştirilen çalışmalar dikkate alınarak çalışanların bencillik davranışlarının motivasyonları üzerindeki etkisi ölçülürken performanslarının aracı etkisi ortaya koyulurken önceki çalışmalarda kullanılan ölçekler ve elde edilen sonuçlar ile yorumlanmıştır. Daha evvel gerçekleştirilen çalışmalarda aracı etkinin ortaya koyulmasında ilgili regression ölçüm modeli sonucunda p değerinin anlamsız ( $\mathrm{p}>0,05)$ olmas1 gerekmektedir (Chiang ve Hsieh, 2012: 184-185; Okan ve Akyüz, 2015: 169-170). Araştırma tablo 8'de elde edilen sonuçlar incelendiğinde; çalışanların bencil davranışları performanslarının negatif $(,-085)$ ve anlamlı $(\mathrm{p}=, 019)$ olarak etkilemiştir (H1b kabul). Çalışanların performansları ise motivasyonlarını pozitif $(, 793)$ ve anlamlı $(\mathrm{p}=, 000)$ olarak etkilemiş̧ir (H1c kabul). Ayrıca çalışanların bencil davranışları motivasyonlarını negatif $(,-063)$ ve anlamsız $(\mathrm{p}=, 078)$ olarak etkilediği (H1a kabul) sonuçlarına ulaşılmıştır. Bu sonuçlar araştırma hipotezlerinin tamamının kabul edildiğini ortaya koymaktadır. Araştırma model 2'ye ilişkin veriler şekil 3'te ortaya koyulmuştur.

\section{Şekil 3: Model 2 Yapısal Eşitlik Modeli Sonucu}

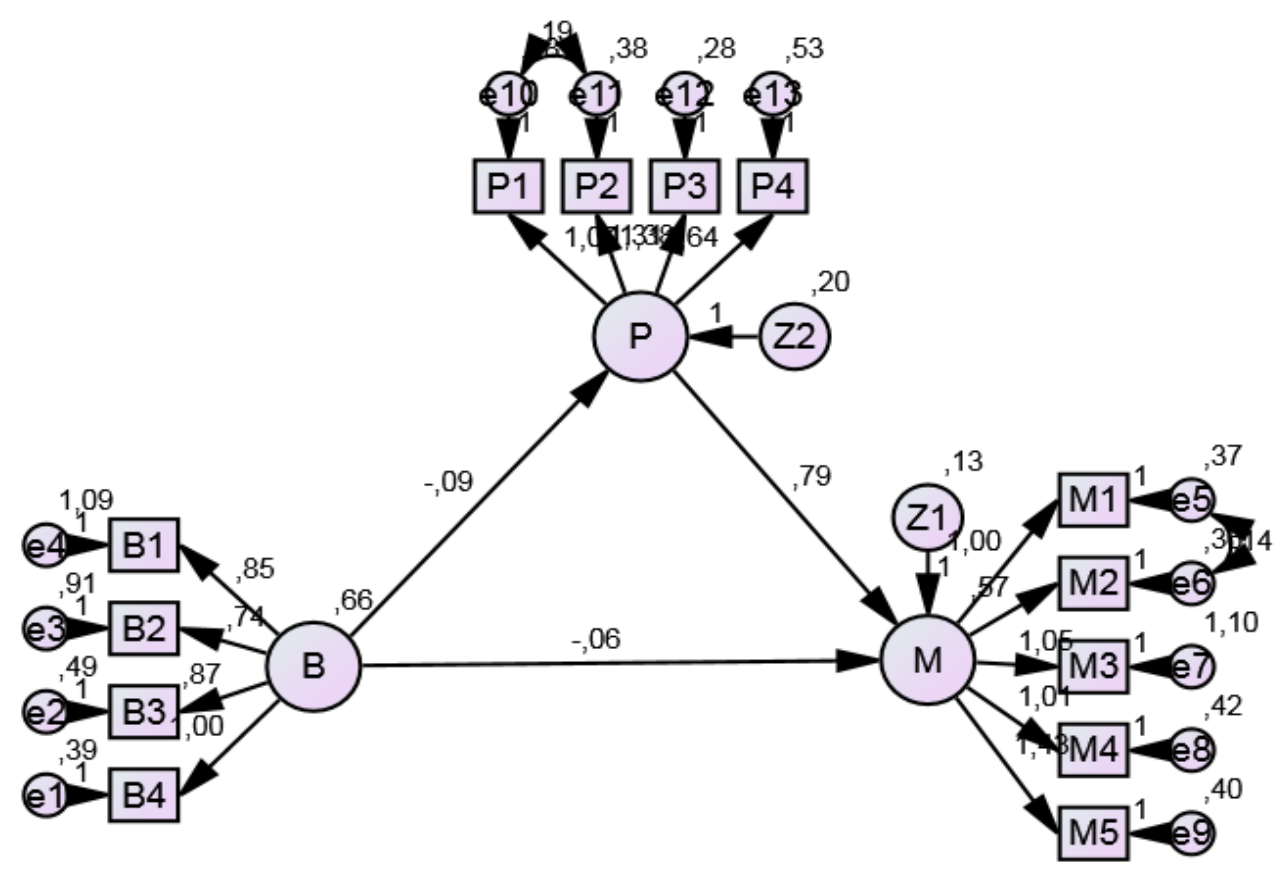

Araştırmada şekil 3'te ifade edilen sonuçlara bakıldığında çalışanların bencil davranışlarının motivasyonları üzerindeki negatif ve anlamsız etkisinde çalı̧̧anların performanslarının tam aracı etkisi olduğu gözlemlenmektedir. $\mathrm{Bu}$ durum çalışanların bencillik davranışlarının motivasyonları üzerinde dolaylı (performans üzerinden) etkilerinin olduğunu ortaya koymaktadır. Çalışma sonuçlarında çalışanların bencillik davranışlarının performanslarını negatif ve anlamlı olarak etkilediği görülmektedir. Ayrıca çalışanların 
performanslarının da motivasyonlarını pozitif ve anlamlı olarak etkilediği çalışma sonuçları ile ortaya koyulmuştur.

\section{SONUÇ VE TARTIŞMA}

Günümüzde farklı sektörlerde faaliyette bulunan çalışanların çalışma ortamındaki bencil davranışları, performansları ve motivasyonları çeşitli sebeplerden ötürü etkilenebilmektedir. $\mathrm{Bu}$ açıdan araştırma sonuçlarında çalışanların bencil davranışlarının performanslarını negatif ve anlamlı olarak, performanslarının motivasyonlarını pozitif ve anlamlı olarak ve bencil davranışlarının da motivasyonlarını negatif ve anlamlı olarak etkilediği sonuçlarına ulaşılmıştır. Ayrıca araştırmada çalışanların bencil davranışlarının motivasyonları üzerindeki etkisinde performanslarının da tam aracı etkiye sahip olduğu gözlemlenmiştir.

Araştırma sonuçlarında çalışanların bencil davranışlarının hem motivasyonlarını hem de performanslarını negatif ve anlamlı olarak etkilediği sonuçlarına ulaşılmıştır. Judge ve Ilies (2004) araştırmalarında çalışanların bencil davranışlarının organizasyon için faydalı olmadığını dile getirmişlerdir. Bevan ve Werhane (2015) çalışmalarında çalışanın kendi çıkarını çalıştığı iş yerinin çıkarlarından daha üstün tutmasının bencilce hareket ettiklerini ortaya koyduğunu ifade etmişlerdir. Chen (2014) ise araştırmasında çalışanlara sunulan sınırlı kaynağın bencilce davranmalarına sebep olabileceğini vurgulamıştır. Dubois ve diğerleri (2015) ise bencillik ile ahlaksız davranışların ilişkili olduğunu ortaya koymuşlardır. Bu sonuçlar çalışanların bencil davranışlarının organizasyon için faydalı olmadığını ortaya koymaktadır. Çalışanların bencilce hareket etmelerine sebep olabilecek bir değişken organizasyonların sağladığı sınırlı kaynaklar olabilir. Çalışanların bencilce davranış sergilemelerine sebep olabilecek başka etmenler de söz konusu olabilir.

Araştırmada çalışanların bencil davranışlarının performanslarını negatif ve anlamlı olarak etkilediği, çalışanların bencil davranışlarının motivasyonlarını negatif ve anlamlı olarak etkilediği, çalışanların performansının ise motivasyonlarını pozitif ve anlamlı olarak etkilediği ve performansın tam aracı etkiye sahip olduğu gözlemlenmiştir. Chaurasia ve Shukla (2014) araştırmalarında üst düzeyde psikolojik sermayeye sahip olan çalışanların daha iyi performans sergileyebileceklerini ifade etmişlerdir. Muogbo (2013) bir örgütte çalışanlara verilen dışsal motivasyonun çalışanların performansı üzerinde önemli etkisinin olduğunu belirtmiştir. Sattar ve diğerleri (2015) İnsan kaynakları çalışmalarının çalışanların performansını olumlu yönde etkileyebileceğini vurgulamışlardır. Akanbi (2011) ise çalışmasında çalışan performansının motivasyondaki artış ile geliştiğini ifade etmiştir. Pandey (1988) güç ve bağl1lık motivasyonunun performans ile pozitif ilişkili olduğunu belirtmişlerdir. Corey (1973) çalışma ortamında çalışanları motive edici faktörleri; çalışan ile işveren arasındaki olumlu iletişim, tatmin edici eğitim olanakları, denetim yetkinliği, yeterli düzeyde tanınma, iş süresindeki güvenlik, işten zevk alma, çalışanlar arasındaki olumlu ilişkiler ve çalışanların teşvik edilmesi gibi faktörlerin etkili olduğunu ifade etmiştir. Hitka ve Balazova (2015) ise bunlara ek olarak maaşın, parasal ödüllerin ve sosyal olanakların çalışanları motive ettiğini ifade etmişlerdir. Zameer ve diğerleri (2014) ise çalışanların iyi motive edilmelerinin performanslarını olumlu yönde etkilediğini ortaya koymuşlardır. Örnek verilen bu çalışmalar dikkate alındığında çalışanların motive edilmesinin (ücret, iş güvencesi, teşvikler gibi) performansları üzerinde olumlu etkilerinin olduğunu ortaya koymaktadır. Araştırmada çalışanların performanslarının motivasyonları üzerinde nasıl bir etki bıraktığı araştırılmış ve pozitif ve anlamlı etkileri olduğu görülmüş̧ür. Bu sonuç çalışanların bencil davranış sergilemelerinin performanslarını olumsuz olarak etkilediğini ancak performansları sonucunda elde ettikleri çıktıların motivasyonlarını pozitif olarak etkilediğini ortaya koymaktadır. Çalışanların iş yerlerinde gösterdikleri performans düzeylerinin yeterli olduğu algısı motivasyonlarını olumlu yönde etkilemiş olabilir. Çalışanların iş yerlerinde motive edici faktörler ile hareket etmeleri sağlanıyor ise çalışanların performansları veya motivasyonları bu durumlardan olumlu olarak etkilenmiş olabilir. Ayrıca çalışmada elde edilen verilerin birçoğu kamuda çalışanlardan oluşmaktadır. Bu durum çalışanların işleri ile ilgili fazla kaygı taşımamalarını ve dolayısı ile performanslarının ve motivasyonlarının bu durumlardan olumlu yönde etkilenmelerine sebep olmuş olabilir.

Sonuç olarak çalışanların bencillik davranışlarının hem motivasyonlarını hem de performanslarını negatif ve anlamlı olarak etkilemesi; çalışanların iş yerlerinde bir bütün içerisinde (ekip gibi) hareket etmeleri gerektiğini ortaya koymaktadır. Bu hem organizasyon hem de çalışanlar açısından daha olumlu sonuçların alınmasını sağlayabilir. Ayrıca çalışanların bencillik davranışlarının motivasyonları dolaylı olarak etkilemesinde performanslarının da oldukça önemli olduğu gözlemlenmiştir. $\mathrm{Bu}$ durum da çalışan motivasyonunun sadece performans öncesi duruma bağlı olmadığını, çalışanların performanslarından sonraki durumlarda da motivasyonlarının önemli olduğu sonucunu ortaya koymaktadır.

\section{Araştırmanın Teorik Katkıları}


Araştırma ile daha önce gerçekleştirilen çalışmalarda dikkate alınarak olası teorik katkılar aşağıdaki gibi ifade edilebilir.

- Çalışanların çalışma ortamındaki bencillik davranışları organizasyon için olumsuz sonuçlar doğurabilir.

- Çalışanların motivasyonları performanslarını genel itibari ile pozitif ve anlamlı olarak etkilemektedir.

- Organizasyonlarda çalışanların motivasyonlarına etki edebilecek birçok faktör söz konusu olabilir.

- Çalışanların iş yerlerindeki motivasyonları ve performanslarının yanında bencillik davranışları da dikkate alınması gerekebilir.

\section{Araştırmanın Pratik Katkıları}

Çalışma ile elde edilen sonuçlara bağlı olarak olası pratik katkılar aşağıdaki gibi ifade edilebilir.

- Çalışanların iş yerlerinde bencil davranışlarına yönelik yeni bir çalışma olması literatüre çalışanların performansları ve motivasyonları açısından farklı bakış açıları kazandırabilir.

- Çalışanların bencillik davranışları performaslarını olumsuz olarak etkilemektedir

- Çalışanların iş yerlerindeki bencillik davranışları motivasyonlarını olumsuz yönde etkilemektedir.

- Daha evvel gerçekleştirilen çalışmalar genellikle çalışanların motivasyonlarının performansları üzerindeki etkilerini ortaya koyarken araştırma ile çalışanların performanslarının motivasyonlarını olumlu yönde şekillendirdiği ortaya koyulmuştur.

- Çalışanların iş yerlerindeki bencil davranışlarının motivasyonları üzerindeki etkisinde performansları tam aracı etkiye sahip olmuştur.

- Çalışanların iş yerlerinde bireysel tutumlarına yönelik bencilce (ben merkezli) hareket etmeleri hem performanslarını hem de motivasyonlarını olumsuz yönde etkilemektedir. $\mathrm{Bu}$ durum iş yerlerinde çalışan bireylerin hem performansları hem de motivasyonları için kolektif hareket etmelerinin organizasyonun bütünlügü açısından da daha olumlu bir etkisi olabileceği yorumunu yaptırabilmektedir.

\section{Araştırma Sınırları}

Literatür yardımı ile uygulamaya koyulan araştırma 2019 yılında Doğu Anadolu ve Doğu Karadeniz Bölgelerinde kamuda ve özel sektörde faaliyette bulunan 412 çalışan ile sınırlıdır. Araştırmada çalışanların bencil davranışları, motivasyonları ve performansları ölçülürken kaynak olarak kendi düşünceleri (elektronik anket yöntemi ile) incelemeye alınmıştır. Bu tarz çalışmalarda çalışanlar dışındaki kişilerin çalışanları üzerindeki gözlemleri (yöneticiler veya örgüt dışındaki kişiler) de dikkate alınabilir. Ayrıca bu tarz çalışmalarda deneysel çalışmalara da başvurulması konunun daha detaylı bir şekilde açıklanabilmesine imkân sağlayabilir.

\section{Gelecek Araştırmalar}

Gelecek araştırmalarda çalışanların çalışma ortamı sadece iş yerleri ile sınırlı tutulmadan çalışanların iş yerleri dışındaki etmenlerin de ne gibi etkilerinin olabileceği ölçülebilir. Örneğin çalışan motivasyonunun sadece iş yeri ile sınır tutulmamasının gündelik hayatta da çalışma ortamına ilişkin düşüncelerin ve etkilerin çalışanların motivasyonunu etkileyebileceği hususunda yeni çalışmalar ortaya koyulabilir. Ayrıca çalışanların çalışma ortamlarındaki performansları ve motivasyonları ölçülürken bencil davranışa yönelmelerine sebep olabilecek (Maddi sıkıntılar mı? Ailevi problemler mi? Güven eksikliği mi? vb.) etmenlerin neler olabileceği yeni araştırmalar ile ortaya koyulabilir ve literatüre farklı bakış açıları kazandırılabilir. 


\section{KAYNAKÇA}

Abbas, Qaisar ve Sara Yaqoob (2009) "Effect of Leadership Development on Employee Performance in Pakistan", Pakistan Economic and Social Review, 47 (2), s.269-292.

Akanbi, Paul Ayobami (2011) “Influence of Extrinsic and Intrinsic Motivation on Employees Performance", Retrieved October, 7, s.1-14

Akaoka, Isao (1983) "Motivation of Employees in Japan”, Kyoto University Economic Review, 53 (1/2), s.25-50.

Ali, Reena ve M. Shakil Ahmed (2009) "The Impact of Reward and Recognition Programs On Employe's Motivation and Satisfaction: An Empirical Study", International Review of Business Research Papers, 5 (4), s.270-279.

Anyim, Chukwudi F., Odogwu C. Chidi ve Adedehinbo E Badejo (2012) "Motivation and Employees Performance in the Public and Private Sectors in Nigeria", International Journal of Businees Administration, 3 (1), s.31-40.

Azar, Maryam ve Ali Akbar Shafighi (2013) "The Effect of Work Motivation on Employees Job Performance (Case Study: Employees of Isfahan Islamic Revolution Housing Foundation)", International Journal of Academic Research in Businees and Social Sciences, 3 (9), s.432-445.

Barrick, Murray R., Greg L. Stewart ve Mike Piotrowski (2002) "Personality and Job Performance: Test of the Mediating Effects of Motivation Among Sales Representatives", Journal of Applied Psychology, 87 (1), s.1-9.

Battal, Fetullah, Durmuş, İbrahim. ve Çınar, Ertuğrul (2017) "The Effects of Organizational Citizenship Behaviors and Decision-Making Styles on Transformational Leadership Behavior", Turkish Studies, 12 (31), s.1-28.

Benston, George J. (1963) “The Role of the Firm's Accounting System for Motivation”, The Accounting Review, 38 (2), s.347-354.

Bevan, David ve Patricia Werhane (2015) “The Inexorable Sociality of Commerce: The Individual and Others in Adam Smith", Journal of Business Ethics, 127 (2), s.327-335.

Biswas, Soumendu (2009) "Organizational Culture \& Transformational Leadership as Predictors of Employee Performance", Indian Journal of Industrial Relations, 44 (4), s.611-627.

Bright, Leonard (2007) "Does Person-Organization Fit Mediate the Relationship Between Public Service Motivation and the Job Performance of Public Employees?", Review of Public Personnel Administration, 27 (4), s.361-379.

Chaurasia, Swati ve Archana Shukla (2014) "Psychological Capital, LMX, Employee Engagement \& Work Role Performance", Indian Journal of Industrial Relations, 50 (2), s.342-356.

Chen, Chung-wen (2014) “'Are Workers More Likely to be Deviant than Managers? A Cross-National Analysis", Journal of Business Ethics, 123 (2), s.221-233.

Chiang, Chun-Fang ve Tsung-Sheng Hsieh (2012) "The Impacts of Perceived Organizational Support and Psychological Empowerment on Job Performance: The Mediating Effects of Organizational Citizenship Behavior”, International Journal of Hospitality Management, 31, s.180-190.

Corey, John B.W. (1973) “Motivating Employees”, Journal (American Water Association), 65 (1), s.39-41.

Cullen, Kristin L., Bryan D. Edwards, Wm. Camron Casper ve Kevin R. Gue (2014) "Employees Adaptability and Perceptions of Change-Related Uncertainty: Implications for Perceived Organizational Support", Journal of Business and Psychology, 29 (2), s.269-280.

Dartey-Baah, Kwasi ve George Kofi Amoako (2011) "Application of Frederick Herzberg's Two-Factor Theory in Assessing and Understanding Employee Motivation at Work: A Ghanaian Perspective", European Journal of Business and Management, 3 (9), s.1-8.

Dubois, David, Derek D. Rucker ve Adam D. Galinsky (2015) "'Social Class, Power, and Selfishness: When and Why Upper and Lower Class Individuals Behave Unethically”, Journal of Personality and Social Psychology, 108 (3), s.436-449.

Dvivedi, R.S. (1980) “Some Correlates of Employee Performance”, Indian Journal of Industrial Relations, 15 (4), s.563576.

Fernandez, Segio ve Tima Moldogaziev (2013) “Employee Empowerment, Employee Attitudes, and Performance: Testing a Causal Model", Public Administration Review, 73 (3), s.490-506.

Forde, David R. ve Leslie W. Kennedy (1997) "Risky Lifestyles, Routine Activities, and the General Theory of Crime", Justice Quarterly, 14 (2), s.265-294.

Gong, Yaping, Jia-Chi Huang ve Jiing-Lih Farh (2009) "Employee Learning Orientation, Transformational Leadership, and Employee Creativity: The Mediating Role of Employee Creative Self-Efficacy", The Academy of Management Journal, 52 (4), s.765-778.

Govindarajulu, Nalini ve Bonnie F. Daily (2004) “Motivating Employees for Environmental Improvement”, Industrial Management \& Data Systems, 104 (4), s.364-372.

Grant, Adam M. (2007) "'Relational Job Design and the Motivation to Make a Prosocial Difference", The Academy of Management Review, 32 (2), s.393-417.

Guo, Yun, Jianq1ao Liao, Shudı Liao ve Yanhong Zhang (2014) "The Mediating Role of Intrinsic Motivation on the Relationship Between Developmental Feedback and Employee Job Performance", Social Behavior and Personality, 42 (5), s.731-742.

Hijazi, Syed Tahir (1999) "Motivational Aspect of Good Governance", The Pakistan Development Review, 38 (4), s.905-912. 
Hitka, Milos ve Zaneta Balazova (2015) “The Impact of Age, Education and Seniority on Motivation of Employees", Business: Theory and Practice, 16 (1), s.113-120.

Jayaweera, Thushel (2015) "Impact of Work Environmental Factors on Job Performance, Mediating Role of Work Motiation: A Study of Hotel Sector in Englang', International Journal of Business and Management, 10 (3), s.271 278.

Jensen, Larry C. ve Steven A. Wygant (1990) “The Developmental Self-Valuing Theory: A Practical Approach for Business Ethics", Journal of Business Ethics, 9 (3), s.215-225.

Kuvaas, Bard (2006) "Performance Appraisal Satisfaction and Employee Outcomes: Mediating and Moderating Roles of Work Motivation'”, The International Journal of Human Resource Management, 17 (3), s.504-522.

Lin, Carol Yeh-Yun ve Feng-Chuan Liu (2012) “A Cross-Level Analysis of Organizational Creativity Climate and Perceived İnnovation”, European Journal of Innovation Management, 15 (1), s.55-76.

Long, Richard J. (2000) "Employee Profit Sharing: Consequence and Moderators', Relations Industrielles / Industrial Relations, 55 (3), s.477-504.

Lu, Luo (1999) “Work Motivation, Job Stress and Employees Well-being”, Journal of Applied Management Studies, 8 (1), s.61-72.

Judge, Timothy A. ve Remus Ilies (2004) "Is Positiveness in Organizations Always Desirable?', Academy of Management Executive, 18 (4), s.151-155.

Manners, George E., Joseph A. Steger ve Thomas W. Zimmerer (1997) “Motivating Your R\&D Staff”, Research Technology Management, 40 (6), s.29-34.

Manzoor, Quratul-Ain (2011) “Impact of Employees Motivation on Organizational Effectiveness", European Journal of Business and Management, 3 (3), s.36-44.

Mintzberg, Henry, Robert Simons ve Kunal Basu (2002) “Beyond Selfishness”, Mit Sloan Management Review, s.6774.

Moberg, Dennis J. (1997) “'On Employee Vice’”, Business Ethics Quarterly, 7 (4), s.41-60.

Muogbo, Uju S. (2013) “The Influence of Motivation on Employees Performance: A Study of Some Selected Firms in Anambra State', An International Journal of Arts and Humanities, 2 (3), s.134-151.

Noval, Laura J. (2016) " On the Misguided Pursuit of Happiness and Ethical Decisions Making: The Roles of Focalism the Impact Bias in Unethical and Selfish Behavior”, Organizational Behavior and Human Decision Processes, 133, s.1-16.

Okan, Tarhan ve Ahmet Mutlu Akyüz (2015) "Exploring the Relationship Between Ethical Leadership and Job Satisfaction with the Mediating Role of the Level of Loyalty to Supervisor', Businees and Economics Research Journal, 6 (4), s.155-177.

Osterloh, Margit ve Bruno S. Frey (2000) “'Motivation, Knowledge Transfer, and Organizational Forms', Organization Science, 11 (5), s.538-550.

Padaki, Rupande (1984) "Job Characteristics and Work Motivation: A Test of Job Desing Model”, Indian Journal of Industrial Relations, 19 (4), s.469-483.

Pandey, Ashok Kumar (1988) “Employees Need Structure and Their Performance', Indian Journal of Industrial Relations, 24 (1), s.84-93.

Perry, James L. ve Lyman W. Porter (1982) "Factors Affecting the Context for Motivation in Public Organizations", The Academy of Management Review, 7 (1), s.89-98.

Porter, Lyman W., Gregory A. Bigley ve Richard M. Steers (2003) “'Motivation and Work Behavior', Conceptual Approaches to Motivation at Work, s.125-140.

Roux, Caroline, Kelly Goldsmith ve Andrea Bonezzi (2015) “On the Psychology of Scarcity: When Reminders of Resource Scarcity Promote Selfish (and Generous) Behavior', Journal of Consumer Research, 42, s.615-631.

Sani, Achmad (2013) "Role of Procedural Justice, Organizational Commitment and Job Satisfaction on Job Performance: The Mediating Effects of Organizational Citizenship Behavior', International Journal of Business and Management, 8 (15), s.57-67.

Sattar, Tehmina, Khalil Ahmad ve Syeda Mahnaz Hassan (2015) "Role of Human Resource Practices in Employee Performance and Job Satisfaction with Mediating Effect of Employee Engagement', Pakistan Economic and Social Review, 53 (1), s.81-96.

Sengupta, Sunita Singh (2011) “Growth in Human Motivation: Beyond Maslow”, Indian Journal of Industrial Relations, 47 (1), s.102-116.

Spence, Jeffrey R. ve Lisa M. Keeping (2010) "The Impact of Non-Performance Information on Ratings of Job Performance: A Policy-Capturing Approach”, Journal of Organizational Behavior, 31, s.587-608.

Spreitzer, Gretchen M. ve Aneil K. Mishra (1999) “'Giving up Control Wihout Losing Control”, Group \& Organization Management, 24 (2), s.155-187.

Thompson, James W. (1996) “Employee Attitudes, Organizational Performance, and Qualitative Factors Underlying Success"', Journal of Business and Psychology, 11 (2), s.171-196.

Tietjen, Mark A. ve Robert M. Myers (1998) 'Motiation and Job Satisfaction', Management Decision, 36 (4), s.226231. 
Tsui, Anne S., Jone L. Pearce, Lyman W. Porter ve Angela M. Tripoli (1997) “Alternative Approaches to the EmployeeOrganization Relationship: Does Investment in Employees Pay off?’, The Academy of Management Journal, 40 (5), s.1089-1121.

Tyagi, Pradeep K. (1985) "Relative Importance of Key Job Dimensions and Leadership Behaviors in Motivating Salesperson Work Performance', Journal of Marketing, 49 (3), s.76-86.

Uzonna, Ukajiofo Rex (2013) “Impact of Motivation on Employees Performance: A Case Study of CreditWest Bank Cyprus", Journal of Economics and International Finance, 5 (5), s.199-211.

Vandenabeele, Wouter (2016) "The Mediating Effect of Job Satisfaction and Organizational Commitment on SelfReported Performance: More Robust Evidence of the PSM-Performance Relationship', International Review of Administrative Sciences, 75 (1), s.11-34.

Welbourne, Theresa M., Diane E. Johnson ve Amir Erez (1998) “The Role-Based Performance Scale: Validity Analysis of a Theory-Based Measure", The Academy of Management Journal, 41 (5), s.540-555.

Wiley, Carolyn (1997) “What Motivates Employees According to Over 40 Years of Motivation Surveys”, International Journal of Manpower, 18 (3), s.263-280.

Wright, Bradley E., Robert K. Christensen ve Kimberley Roussin Isett (2013) “Motivated to Adapt? The Role of Public Service Motivation as Employees Face Organizational Change’, Public Administration Review, 73 (5), s.738747.

Yuan, Feirong ve Richard W. Woodman (2010) "Innovative Behavior in the Workplace: The Role of Performance and Image Outcome Expatations", The Academy of Management Journal, 53 (2), s.323-342.

Yusoff, W.F. Wan, Tan Shen Kian ve Mohammad T.M. Idris (2013) 'Herzberg's two Factors Theory on Work Motivation: Does its Work for Todays Environment?', Global Journal of Commerce \& Management Perspective, $2(5)$, s. $18-22$.

Zameer, Hashim, Shehzad Ali, Waqar Nisar ve Muhammad Amir (2014) "The Impact of the Motivation on the Employee's Performance in Beverage Industry of Pakistan', International Journal of Academic Research in Accounting, Finance and Management Sciences, 4 (1), s.293-298.

Zhang, Mingqiong, David Di Fan ve Cherrie Jiuhua Zhu (2014) "High-Performance Work Systems, Corporate Social Performance and Employee Outcomes: Exploring the Missing Links', Journal of Business Ethics, 120 (3), s.423435. 